\title{
The onset of rheumatoid arthritis and systemic lupus erythematosus following influenza vaccination: Report of three cases
}

\author{
Arthur E Brawer* and Sai Koyoda \\ Department of Medicine, Division of Rheumatology, Long Branch, USA
}

\begin{abstract}
Standard dose, inactivated, trivalent influenza vaccine was administered in 2009 to two healthy women age 46 and 56 . Another woman, age 29 , received an unspecified influenza vaccine in 2013. The first two developed rheumatoid arthritis, and the third developed systemic lupus erythematosus, all in close proximity to their immunizations. All three disease processes remained chronic, requiring continuous standard treatment.
\end{abstract}

\section{Introduction}

A variety of environmental risk factors are capable of triggering the onset of rheumatoid arthritis (RA) and systemic lupus erythematosus (SLE). These include (but are not limited to) infections, physical trauma, severe emotional upset, drugs, insecticides, pesticides, smoking, periodontitits, hypoxia, hormonal imbalances, foods, ultraviolet light, prolonged exposure to unusual temperature changes, chemical pollution, poor nutrition, microbiota imbalances, and vaccinations [1-5]. With regard to vaccinations, numerous immunizations against a wide variety of infectious agents have been reported to be the initiating triggers associated with the onset of many autoimmune diseases, including inflammatory systemic connective tissue diseases, the latter of which encompass RA, SLE, polymyositis (PM), dermatomyositis (DM), ANCA associated vasculitis (AAV), polymyalgia rheumatica (PMR), giant-cell arteritis (GCA), and reactive arthritis [4-17]. The following three case reports, although clearly not novel first-time observations, add to a growing list of published adverse autoimmune rheumatologic phenomena following influenza vaccination and reinforce prior alerts for physician awareness of these occurrences.

\section{Case report 1}

A 46-year-old female physical therapist, on no medications and not suffering from any definable chronic medical or rheumatic ailments, received a standard inactivated trivalent influenza vaccine in the fall of 2009. Within 24 hours she began to complain of pain and stiffness in multiple small and large joints symmetrically, which continued on a daily basis. Six weeks later physical examination revealed swelling, limited motion, and pain on motion in both wrists, similar observations in the MCP's and PIP's of her hands, and ankle swelling, accompanied by pain on motion in her shoulders and hips and two hours of morning stiffness. Rheumatoid factor via SCAT (sheep cell agglutination test) was positive, and a diagnosis of rheumatoid arthritis was made. Over the next four years her RA proved refractory to NSAID's, hydroxychloroquine, methotrexate, leflunamide, and corticosteroids. Subsequently treatment with etanercept was instituted, resulting in substantial and sustained improvement (but by no means resolution) of her systemic inflammation. Any attempt over the next five years to discontinue this remitting therapy resulted in a prompt exacerbation of her RA.

\section{Case report 2}

A 56-year-old female with a history of penicillin allergy and osteoarthritis in her knees received a standard inactivated trivalent influenza vaccine in the fall of 2009. Eight hours later she developed progressively intense left shoulder pain, accompanied three days later by pain and swelling in her left hand. Five days after her vaccination she noted pain and swelling in both wrists and her right hand, followed four days later by pain in both ankles and feet. Her acute arthritis remained unremitting, and within one month of her influenza vaccination pain and stiffness and limited motion developed in her right shoulder. Two months later blood tests revealed a positive rheumatoid factor and and elevated sedimentation rate of 62 . Rheumatology consultation five months after her vaccination verified a definitive diagnosis of rheumatoid arthritis, whereupon prednisone, methotrexate and hydroxychloroquine were prescribed. Despite significant improvement her polyarthritis has continued unabated.

\section{Case report 3}

A 29-year-old female, in excellent health and on no medications, received an unspecified influenza vaccine in the fall of 2013. Within 24 hours she developed fatigue which persisted unabated. Two weeks later she developed a chronic headache, myalgias in her calves and upper arms, arthralgias in multiple small and large joints, and

*Correspondence to: Arthur E Brawer, Monmouth Medical Center, Department of Medicine, Division of Rheumatology, 300 Second Avenue, Long Branch, New Jersey 07740, USA, Tel: +732-870-3133, Fax: +732-222-0824, E-mail: arthurbrawer@optimum.net

Key words: influenza vaccination, rheumatoid arthritis, systemic lupus erythematosus, immunizations and autoimmunity

Received: August 08, 2019; Accepted: August 16, 2019; Published: August 19, 2019 
classical fortification spectra, the latter characterized by overlapping irregular and jagged "rings" permeated by a diversity of different colors. Shortly thereafter tingling and numbness developed in her toes, accompanied by weakness in her extremities. A neurologist performed an examination of spinal fluid, revealing a mild pleocytosis. Further testing revealed a five-fold elevation of $\mathrm{CPK}$, hemolytic anemia with a positive direct Coombs, thrombocytopenia, and a positive ANA (antinuclear antibody) test in a titer of 1:160. Urinalysis and other serologic tests were normal or negative. She was diagnosed with systemic lupus erythematosus and was treated with chronic oral corticosteroids and six weeks of intravenous gammaglobulin, resulting in substantial improvement (but by no means resolution) of all clinical phenomena. One year later she developed malar erythema, and shortly thereafter a pregnancy ended with death in utero at ten weeks gestation despite concomitant progesterone supplementation. Testing for antiphospholipid antibodies was negative. Over the next four years there has been no evidence for Raynaud's, Sjogren's, photosensitivity, hair loss, renal disease, or seizures. Present treatment consists of low dose prednisone and hydroxychloroquine.

In all three patients there is no family history of inflammatory systemic connective tissue diseases, nor had anyone previously received any type of influenza vaccination. Historical data on other prior vaccinations (tetanus, pertussis, hepatitis, etc.) were not recorded. Generalized allergic diatheses were not manifested by any of the three patients. Previous serologic testing for autoantibodies (prior to influenza vaccination) had not been performed on anyone.

\section{Discussion}

On March 23, 2011, in the United States Court of Federal Claims, Special Master Patricia E. Campbell-Smith issued a ruling (unrelated to these three cases), asserting that Hepatitis $B$ vaccine was the cause of systemic lupus erythematosus [18]. Five years later, in case 1 of this report, a final verdict was rendered by a different special master stating that influenza vaccine caused rheumatoid arthritis (verdicts in cases 2 and 3 are still pending). The venue for these decisions was created in 1986 and is known as the National Vaccine Injury Compensation Program, a no-fault alternative to the traditional legal system for resolving vaccine injuries. Special Masters are not judges, but rather federal employees, and the standard of proof in "vaccine court" is vastly different than in a routine court of law. We acknowledge that judicial rulings are not the equivalent of scientific investigations, and we also acknowledge publications supporting the efficacy and safety of various influenza vaccines [19-21]. In addition, a temporal association of autoimmunity following vaccination is not synonymous with causation, the latter of which requires careful epidemiologic studies. Nonetheless, these three case reports, when coupled with the references cited in the introduction section of this manuscript, are a testimony to the existence of adverse autoimmune reactions initiated by influenza immunization. Over the past thirty years researchers have proposed a variety of medical theories to explain this reality, and current immunologic observations are proving insightful [5,22-24]. With these advances it is becoming obvious that immunologic mechanisms in the first few days and weeks of vaccineinduced autoimmunity are quite different from definable immunologic events transpiring in patients with spontaneous autoimmune disease onset $[23,24]$. These scientific publications enhance our understanding of how vaccinations produce injury and lend evidence to cause and effect. One such mechanism, however, is drawing intense criticism lately from the medical community, namely ASIA (autoinflammatory syndrome induced by adjuvants, or Shoenfeld's syndrome) [25-28]. As a result, since 2015 the special masters in vaccine court in Washington,
D.C. will no longer allow ASIA to be referenced by any experts testifying on behalf of vaccine injury claimants [28].

The incidence of autoimmune reactions to influenza vaccines is currently unknown, but it can no longer be assumed that a coincidental (i.e., unrelated) association exists between immunization and the onset of RA and SLE. It would be ideal if researchers could eventually determine which individuals are at risk for such phenomena, including delineation of an acceptable definitive time span between vaccination and disease onset. Until then, physicians will need to do the next best thing, namely become aware of vaccine-induced rheumatologic autoimmunity and its potential to persist indefinitely.

\section{Acknowledgement}

There has been no financial support, nor any other benefits from any commercial source, for the work reported in this manuscript. This manuscript has not been submitted elsewhere, nor has it been published elsewhere.

\section{References}

1. Brawer A, Goel N (2016) The onset of rheumatoid arthritis following trauma. Open Access Rheumatol 8: 77-80. [Crossref]

2. Morand EF (2018) Stress and the onset of SLE. Nat Rev Rheumatol 14: 127-128 [Crossref]

3. Brawer A (2018) What do fibromyalgia, chronic fatigue syndrome, and dysautonomia have in common with systemic lupus erythematosus? Open Access 3: 1-2.

4. Vadala M, Poddighe D, Laurino C, Palmieri B (2017) Vaccination and autoimmune diseases: is prevention of adverse health effects on the horizon? EPMA J 8: 295-311. [Crossref]

5. Schattner A (2005) Consequence or coincidence? The occurrence, pathogenesis and significance of autoimmune manifestations after viral vaccines. Vaccine 23: 3876-3886. [Crossref]

6. Brown MA, Bertouch IV (1994) Rheumatic complications of influenza vaccination Aust NZ J Med 24: 572-573. [Crossref]

7. Wang B, Shao X, Wang D, Xu D, Zhang JA (2017) Vaccinations and risk of systemic lupus erythematosus and rheumatoid arthritis: a systemic review and meta-analysis. Autoimmunity Reviews 16: 756-765. [Crossref]

8. Ferri C, Colaci M, Manzini CU, Sebastiani M, Giuggioli D, et al. (2012) Polymyositis following pandemic influenza A (H1N1) and 2009-2010 seasonal trivalent vaccines. Case Reports Rheumatol 2012: 836930

9. Symmons DPM, Chakravarty K (1993) Can immunization trigger rheumatoid arthritis? Ann Rheumatic Dis 52: 843-844. [Crossref]

10. Older SA, Battafarano DF, Enzenauer RJ, Krieg AM (1999) Can immunization precipitate connective tissue disease? Report of five cases of systemic lupus erythematosus and review of the literature. Sem Arthritis Rheumatism 29: 131-139. [Crossref]

11. Agmon-Levin N, Zafrir Y, Paz Z, Shilton T, Zandman-Goddard G, et al. (2009) Ten cases of systemic lupus erythematosus related to hepatitis B vaccine. Lupus 18: 11921197. [Crossref]

12. Soriano A, Verrecchia E, Mariano A, Giovinale M, Fonnesu C, et al. (2012) Giant cell arteritis and polymyalgia rheumatica after influenze vaccination: report of 10 cases and review of the literature. Lupus 21: 153-157. [Crossref]

13. Stubgen JP (2014) A review on the association between inflammatory mhyopathies and vaccination. Autoimmunity Reviews 13: 31-39. [Crossref]

14. Soldevilla HF, Briones SFR, Navarra SV (2012) Systemic lupus erythematosus following HPV immunization or infection? Lupus 21: 158-161. [Crossref]

15. Birck R, Kaelisch I, Schnuelle P, Flores-Suarez LF, Nowack R (2009) ANCA-associated vasculitis following influenza vaccination: causal association or mere coincidence? $J$ Clin Rheumatol 15: 289-291. [Crossref]

16. Altman A, Szyper-Kravitz M, Schoenfeld Y (2008) HBV vaccine and dermatomyositis is there an Association? Rheumatol Int 28: 609-612. [Crossref]

17. Soriano A, Nesher G, Shoenfeld Y (2015) Predicting post-vaccination autoimmunity: Who might be at risk? Pharmacol Res 92: 18-22. [Crossref] 
18. Case number 01-499V, United Sates Court of Federal Claims, Office of Special Masters: Louonia Deniece Harris, administratrix of the estate of Tambra Harris, petitioner, versus Secretary of the Department of Health and Human Services, Respondent.

19. Ray P, Black S. Shinefeld H, Dillon A, Carpenter D, et al. (2011) Risk of rheumatoid arthritis following vaccination with tetanus, influenza, and hepatitis B vaccines among persons 15-59 years of age. Vaccine 29: 6592-6597. [Crossref]

20. Harris KM, Maurer J, Kellermann AL (2010) Influenza vaccine-safe, effective, and mistrusted. $N$ Engl J Med 363: 2183-2185. [Crossref]

21. Treanor JJ (2016) Influenza vaccination. $N$ Engl J Med 375: 1261-1268. [Crossref]

22. Sutjita M, Hohmann A, Comacchio R, Bradley J (1988) Polyspecific human and murine antibodies to diphtheria and tetanus toxoids and phospholipids. Clin Exp Immunol 73: 191-197. [Crossref]

23. Stojanovic M, Petrusie V, Zivkovic I, Inie-Kanada A, Stojicevic I, et al. (2013) Role of molecular mimicry and polyclonal cell activation in the induction of pathogenic B2-glycoprotein 1-directed immune response in Balb/c mice upon hyperimmunization with tetanus toxoid. Immunol Res 56: 20-31. [Crossref]
24. van Aalst S, Ludwig IS, van der Zee R, van Eden W, Broere F (2017) Bystander activation of irrelevant $\mathrm{CD} 4+\mathrm{T}$ cells following antigen-specific vaccination occurs in the presence and absence of adjuvant. Plos One 5: pe0177365. [Crossref]

25. Hawkes D, Benhamu J, Sidwell T, Miles R, Dunlop RA (2015) Revisiting adverse reactions to vaccines: a critical appraisal of autoimmune syndrome induced by adjuvants (ASIA). J Autoimmun 59: 77-84. [Crossref]

26. Ameratunga R, Langguth D, Hawkes D (2018) Perspective: scientific and ethical concerns pertaining to animal models of autoimmune/autoinflammatory syndrome induced by adjuvants (ASIA). Autoimmunity Reviews 17: 435-439. [Crossref]

27. Brawer A (2017) Mechanisms of breast implant toxicity: will the real ringmaster please stand up. Int Annals of Med 1: 249.

28. Brawer A (2017) Autoinflammatory syndrome induced by adjuvants (ASIA) syndrome is misguided. Natural Med $J$ 9: 5 .

Copyright: (C2019 Brawer AE. This is an open-access article distributed under the terms of the Creative Commons Attribution License, which permits unrestricted use, distribution, and reproduction in any medium, provided the original author and source are credited. 